\title{
Gestão de relacionamento com fornecedores em arranjos produtivos locais: o caso do Vale da Eletrônica
}

\author{
Ronan de Brito Murad ${ }^{a *}$, Renato da Silva Lima ${ }^{\mathrm{b}}$, Mário Sacomano Neto ${ }^{\mathrm{c}}$ \\ a*ronanbm@ufmg.br, UNIFEl, Brasil \\ brslima@unifei.edu.br, UNIFEl, Brasil \\ 'msacomano@ufscar.br, UFSCAR, Brasil
}

\begin{abstract}
Resumo
Este artigo analisa a gestão dos relacionamentos com fornecedores, por meio do método de Olsen \& Ellram, em cinco empresas tecnológicas de pequeno e médio porte situadas no arranjo produtivo local (APL) do Vale da Eletrônica em Santa Rita do Sapucaí, MG. 0 estudo tem caráter exploratório, descritivo e a coleta de dados foi realizada in loco através de entrevistas com executivos dessas cinco empresas. Conclui-se que existe uma elevada necessidade de as empresas firmarem parcerias tecnológicas junto aos fornecedores devido à possibilidade do aumento de competitividade atrelada à tecnologia. Entretanto, os relacionamentos com fornecedores ainda são incipientes e informais, sem o suporte de estratégias e sistemas de integração. Devido à utilização de insumos de alta tecnologia, a integração com os fornecedores tem elevado potencial de melhorar a competitividade das empresas. Entretanto, para fomentar esse potencial, o APL e suas instituições necessitam desenvolver políticas de incentivo e ações conjuntas.

Palavras-chave
\end{abstract}

Gestão de relacionamento com fornecedores. Arranjo produtivo local. Pequenas e médias empresas.

\section{Introdução}

A década de 1980 é reconhecida pela literatura como a fronteira histórica entre o papel burocrático do gerenciamento dos materiais e a função estratégica da gestão do relacionamento com fornecedores. Historicamente, o gerenciamento dos materiais estava concentrado no setor de compras, o qual assumia um papel passivo na estratégia das empresas e priorizava somente a redução de custos, desconsiderando uma série de fatores estratégicos. 0 reconhecimento do valor estratégico da gestão de relacionamento com fornecedores surgiu com a percepção de que os custos de compras representam mais da metade do faturamento das empresas. As turbulências vividas em função da crise do petróleo e da falta de matéria-prima também contribuíram para essa mudança de visão empresarial (Spekman \& Hill, 1980; Kraljic, 1983).

Apesar da evolução da gestão do relacionamento com fornecedores nas últimas décadas, o assunto ainda se concentra nas grandes empresas. Existem poucos estudos sobre o relacionamento com fornecedores em pequenas e médias empresas. Mudambi et al. (2004) apontam para a informalidade dos relacionamentos na pequena empresa e alta assimetria de poder nas negociações com grandes empresas. Além do assunto ser pouco explorado na literatura, estudar os relacionamentos com fornecedores em pequenas e médias empresas (PMEs) é importante porque essas organizações são elementos essenciais para a prosperidade econômica de vários países (Amato Neto, 2000; MacGregor et al., 2005). No Brasil, as micro, pequenas e médias empresas classificadas como indústrias extrativas e de transformação sustentam 59\% dos empregos do setor (Instituto Brasileiro de Geografia e Estatística, 2006).

Dentre as diversas tipologias de rede de empresas presentes na literatura, este trabalho centra-se no termo aglomerado (cluster) definido como uma aglomeração geográfica e setorial de empresas e 
instituições associadas (Porter, 1998). Outro termo também usado no Brasil é arranjos produtivos locais (APLs):

[...] aglomerações de empresas em um mesmo território que apresentam especialização produtiva e cooperam entre si e com outras organizações como governo, ensino e instituições de crédito. (Sebrae, 2007, p. 1).

As defasagens em pequenas organizações, tantos gerenciais quanto tecnológicas, decorrem de uma série de limitações, das quais algumas estão apontadas neste artigo. Uma forma encontrada pelas pequenas organizações para superar essas limitações foi desenvolver relações de cooperação em arranjos produtivos locais (APL). Os benefícios dos arranjos produtivos locais estão nos chamados ganhos de eficiência coletiva (Humphrey \& Schmitz, 1998) e estão associados à presença de mão de obra especializada, fornecedores e ganhos de tecnologia através dos transbordamentos.

É importante destacar que os dois aspectos básicos para a caracterização do APL, concentração geográfica e setorial, não são suficientes por si sós para obterem os benefícios chamados por Porter (1998) de ganho de eficiência coletiva decorrente das vantagens de demanda local e do acesso a infraestrutura e recursos humanos regionais. Humphrey \& Schmitz (1998) também apontam um conjunto de fatores que ajudam no alcance do benefício geral de eficiência coletiva: divisão do trabalho e da especialização entre produtores, fornecedores de matérias-primas e de máquinas; agentes que vendam para mercados distantes; empresas especialistas em serviços tecnológicos, financeiros e contábeis; uma classe de trabalhadores assalariados com qualificações e habilidades específicas e associações para a realização de tarefas específicas para o conjunto de seus membros. Dadas as deficiências das PMEs e as eficiências geradas pelo APL, torna-se interessante estudar os relacionamentos de PMEs pertencentes a um APL com seus respectivos fornecedores.

Para nortear a coleta e análise dos dados foram estabelecidas as seguintes questões da pesquisa: Quais são as necessidades de relacionamento com fornecedores das empresas estudadas de um arranjo produtivo local (APL)? Como são os relacionamentos praticados com fornecedores? Quais são as influências da cooperação interna do APL nesses relacionamentos com seus fornecedores? Quais são as principais dificuldades e potenciais de melhoria? A fim de responder às questões propostas, foi feito um estudo de cinco casos múltiplos em empresas do APL de Santa Rita do Sapucaí, MG, o Vale da Eletrônica. A escolha do Vale da Eletrônica deve-se ao destaque do APL no cenário nacional, à composição predominante de pequenas e médias empresas e da natureza do setor de atuação - eletroeletrônico -, o qual possui uma grande variedade de componentes comprados, tornando assim a gestão de fornecedores complexa e de extrema importância para o êxito empresarial.

\section{Gestão de relacionamento com fornecedores}

\subsection{Portfólio de relacionamentos com fornecedores}

Os métodos de portfólio apresentados a seguir auxiliam no entendimento do valor estratégico de cada item de compra, pois propõem desenvolver estratégias distintas para cada tipo de mercado fornecedor e categoria de itens comprados (Van Weele, 2002). Kraljic (1983) introduziu o primeiro método de portfólio com base no poder de compra. Esse modelo "[...] é considerado como uma importante quebra de paradigmas na área de compras e suprimentos [...]”, relatam Gelderman e Van Weele (2002, p. 1). Apesar de inovador, o método de Kraljic (1983) pautou-se no usufruto do poder de compra e mostra-se insuficiente para atuar em decisões de relacionamento com fornecedores (Olsen \& Ellram, 1997; Lilliecreutz \& Ydreskog, 1999).

Já o método de Olsen \& Ellram (1997) é uma evolução da proposta de Kraljic (1983) e foi concebido com o objetivo de desenvolver estratégias para relacionamento com fornecedores. A primeira etapa consiste em avaliar as compras da empresa de acordo com a importância estratégica da compra e a dificuldade de gerenciá-la e situá-la na matriz, como apresentado na Figura 1. Na segunda etapa avaliam-se os relacionamentos com os fornecedores através da sua atratividade relativa e da força do relacionamento. A partir das informações geradas

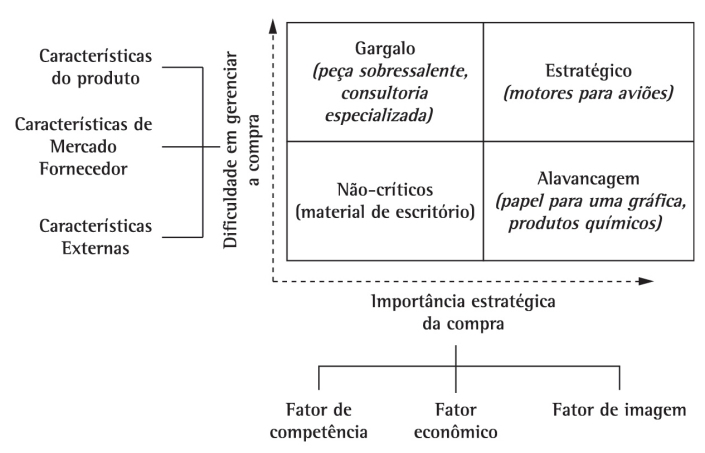

Figura 1. Matriz adaptada de Kraljic (1983) (Olsen \& Ellram, 1997). 
na primeira e segunda etapa, a terceira designa as possíveis decisões de relacionamento com fornecedores.

Nesta pesquisa, foi usada somente a primeira etapa desse método através do qual inferiu-se quais são as necessidades das empresas estudadas no relacionamento com fornecedores. A segunda e terceira etapas auxiliam decisões estratégicas como troca, seleção e desenvolvimento de fornecedores, por isso não estão no foco deste artigo.

De acordo com a primeira etapa do método, para estabelecer a posição das compras na matriz de Kraljic (1983) (Figura 1), cada eixo está dividido em fatores. 0 eixo horizontal de importância estratégica está dividido em três fatores:

- Competência - Visa investigar e avaliar a participação do item comprado na competência do negócio e tecnológica da empresa. Ou seja, esse fator mensura a intensidade com que a compreensão do item de compra auxilia no desenvolvimento do negócio;

- Econômico - Tem como objetivo entender e avaliar a participação do item comprado na rentabilidade da empresa. Um dos levantamentos possíveis para esse fator é o percentual do item comprado nos custos totais de aquisição; e

- Imagem - Possui a finalidade de avaliar o impacto do item comprado na imagem da empresa. Um questionamento cabível nesse fator é se a marca do item comprado possui importância na comercialização dos produtos onde ele é aplicado.

0 eixo vertical Dificuldade de gerenciar a compra também é medido por outros três fatores:

- Características do produto - Avalia a complexidade do item comprado. Por exemplo, se passa por frequentes inovações tecnológicas ou se o produto tem uma tecnologia de alta complexidade esse fator receberá uma qualificação alta;

- Características do mercado fornecedor - Mensura o quanto a empresa está dependente de um determinado fornecedor por questões do mercado (assimetria de poder) e/ou pela competência técnica e comercial do fornecedor; e

- Características externas - Envolve a avaliação de risco e incerteza associada à compra. Inclui riscos decorrentes do comportamento oportunístico do mercado fornecedor, da incerteza de oferta e preços e também da técnica do produto/serviço fornecido.

Com relação a esses critérios, os autores alertam para os ajustes necessários, de acordo com a organização, porque eles não são abrangentes e podem variar conforme aplicação. Além disto, para classificar as compras no método de portfólio, a empresa precisa atribuir pesos e valores aos fatores baseados na percepção dos gestores e das informações da organização (Olsen \& Ellram, 1997; Gelderman,
2003). Dentre as várias metodologias para atribuição de pesos para um número significativo de critérios, Olsen \& Ellram (1997) escolheram a metodologia descrita por Narasimhan (1983). Com a metodologia, é possível estabelecer a posição da compra entre as quatro categorias - Não críticas, Alavancagem, Gargalo e Estratégica (Figura 1).

\subsection{Estilo de relacionamento com fornecedores}

Perona \& Saccani (2004) defendem a existência de quatro estilos de relacionamento com fornecedores - Relacionamento tradicional, Parceria operacional, Parceria tecnológica e Parceria envolvida - suportados pelas técnicas de integração - decisões de como gerenciar o relacionamento - e pelas ferramentas de integração que as suportam (Figura 2). Esses quatro estilos estão descritos a seguir:

- Relacionamento tradicional - Caracteriza-se pela falta de integração entre cliente-fornecedor. Os fornecedores apenas garantem um nível mínimo de serviço e qualidade e o preço segue as regras básicas do mercado. Não é feito nenhum investimento específico por ambas as partes e as empresas, geralmente, exploram o poder de barganha sob a perspectiva de curto prazo (Perona \& Saccani, 2004). Esse tipo de relacionamento pode ser aplicado à categorias de itens Não críticos descrita na seção anterior, pois trata-se de uma compra cujo foco não está no relacionamento e sim na redução de custos, especialmente administrativos;

- Parceria operacional - Caracteriza-se pela necessidade de cortar os gastos provenientes do alto volume comprado e melhorar o nível de qualidade e serviço do item comprado (Saccani \& Perona, 2007). Na perspectiva do fornecedor, além da redução dos custos, essa parceria pode favorecê-lo na mitigação

\begin{tabular}{|l|l|}
\hline $\begin{array}{l}\text { Parceria tecnológica } \\
\text { Ex: } \\
\text { Projeto de produto } \\
\text { compartilhado - TÉCNICA; } \\
\text { Integração dados da } \\
\text { Engenharia } \\
\text { (EDM) - FERRAMENTA. }\end{array}$ & \multicolumn{1}{|c|}{$\begin{array}{c}\text { Parceria envolvida } \\
\text { (Ambas as parcerias) }\end{array}$} \\
\hline & \\
\hline $\begin{array}{l}\text { Relacionamento } \\
\text { Tradicional } \\
\text { (regras de mercado) }\end{array}$ & $\begin{array}{l}\text { Parceria Operacional } \\
\text { Ex: } \\
\text { CRP (Programa de reposição } \\
\text { contínua) - TÉCNICA; } \\
\text { Troca eletrônica de dados } \\
\text { (EDI) - FERRAMENTA. }\end{array}$ \\
\hline
\end{tabular}

Figura 2. Estilos de relacionamento com fornecedor (Perona \& Saccani, 2004). 
dos riscos através de um planejamento de longo prazo da capacidade de produção, pedidos mais confiáveis e previsão de demanda transmitida. Algumas técnicas de integração adequadas a essa parceria são, por exemplo, a reposição contínua (CRP - Continuos Replenishment Process) ou estoque gerenciado pelo fornecedor (VMl - Vendor Managed Inventory), a certificação de qualidade, processos de homologação do fornecedor e auditorias periódicas. Essas técnicas de integração são adequadas para compras em que o volume é relativamente alto, o que geralmente caracteriza na matriz de Kraljic (1983) as compras como de alta importância estratégica (eixo horizontal), pois um dos fatores desse eixo é o volume financeiro e físico da compra. Nessa condição, pode-se dizer que a parceria operacional é um estilo de relacionamento geralmente apropriado às categorias de Alavancagem e Estratégica, a "importância estratégica da compra" é de média a alta;

- Parceria tecnológica - Consolida a integração do fornecedor devido à lacuna de conhecimento técnico do cliente. Algumas técnicas que exemplificam essa parceria são: o projeto de produto para a cadeia de suprimentos; a engenharia virtual; o projeto em conjunto; o compartilhamento de informações acerca dos projetos de desenvolvimento como desenhos; os cronogramas; e as lista de requisitos. Um dos fatores componentes do eixo vertical Dificuldade de gerenciar a compra (Figura 1), tratam-se das características do produto cujos critérios sugeridos envolvem a novidade tecnológica e a complexidade. As técnicas de integração de parceria tecnológicas são apropriadas para compras cujo desenvolvimento de produto e tecnologia têm impactos significativos no comprador. Logo, pode-se afirmar que a parceria tecnológica é, na maioria das vezes, o estilo de relacionamento apropriado para as categorias de itens de Gargalo e Estratégicos, para os quais a dificuldade de gerenciar a compra é alta; e

- Parceria envolvida - Ocorre quando as parcerias tecnológicas e operacionais são conduzidas concomitantemente. Segundo Saccani \& Perona (2007), esse estilo de relacionamento é caracterizado por alto nível de cooperação e interação ao longo do tempo. A parceria envolvida ocorre para produtos que são desenvolvidos em conjunto (fornecedorcomprador) e também conduzidos com uma intensa integração operacional com a sincronização da demanda, redução de estoque, custo de transporte e de qualidade. Pode-se dizer que, na maioria das vezes, a parceria envolvida é demandada por itens de alta importância da compra (eixo horizontal) e de alta dificuldade no gerenciamento da compra (eixo vertical), ou seja, itens estratégicos.

Essenciais para que as parcerias, tanto operacionais quanto tecnológicas, ocorram, as técnicas de integração determinam como gerenciar o processo de interface com o fornecedor. Alguns exemplos de técnicas de integração são os programas de ressuprimento automático (CRP), de qualidade assegurada e desenvolvimento conjunto, pois gerenciam de uma forma específica o fornecedor. Contudo, as implementações das técnicas de integração necessitam de mecanismos capazes de apoiá-las. Nesse sentido, as ferramentas de integração podem ser definidas como o recurso ou capital dedicado à implantação de uma ou mais técnicas de integração. Por exemplo, uma técnica de gestão como CRP pode ser suportada por uma ferramenta de integração como EDI (Electronic Data Interchange). Outros exemplos de ferramentas são sistemas CAD/CAM, integração de dados via internet e mecanismos de qualificação de fornecedores.

\section{Método de pesquisa}

Este estudo classifica-se como exploratório, descritivo e qualitativo, conforme denominam Collins \& Hussey (2005). A fim de atender ao objetivo da pesquisa, o método de estudo de casos múltiplos foi escolhido. 0 estudo de caso aprofunda a investigação acerca de um ou mais objetos com a finalidade de compreender um fenômeno e suas fronteiras, sugerir hipóteses, questões ou desenvolver a teoria (Miguel, 2007). Segundo Yin (1994), o estudo de caso pode ser conduzido em fenômenos sob os quais o pesquisador não possui influência e controle. Por isto e pela necessidade de investigar a diversidade das empresas que compõem o APL, os estudos de casos múltiplos são mais adequados para o propósito deste estudo.

De acordo com Voss et al. (2002), este estudo é classificado como descritivo e exploratório, pois seu objetivo é caracterizar a gestão dos relacionamentos com fornecedores em um APL. Em outras palavras, a pesquisa visa compreender os aspectos específicos de um assunto pouco explorado e ainda tratado pela literatura de forma ampla. Além de descritivo, o método deste artigo é indutivo, porque almeja fornecer resultados que, a partir de constatações particulares, permitem aos estudos posteriores generalizações.

Alinhada com o objetivo e com o fenômeno em estudo, a abordagem desta pesquisa é qualitativa com entrevistas em profundidade. Procurou-se levantar os aspectos relevantes do contexto através de entrevistas semiestruturadas com os gerentes responsáveis por compras e desenvolvimento de produto de cada uma das empresas.

\subsection{Etapas da pesquisa}

Foi solicitada ao responsável por compras, antes do início das entrevistas, a seleção de quatro itens de compra que se encaixassem nas características definidas no Tabela 1. Este apontamento evitou 
declarações generalistas dos entrevistados em relação aos relacionamentos praticados porque induziu a fornecer exemplos concretos e distintos.

A partir da definição dos quatro itens de análise, as entrevista seguiram quatro etapas conforme mostrado na Figura 3.

Essas etapas envolveram a avaliação e posicionamento dos quatro itens, os procedimentos de compra e os relacionamentos com os fornecedores e, por fim, os relacionamentos com as empresas e a associação gestora do APL.

\subsection{Descrição dos casos estudados}

As cinco empresas entrevistadas fazem parte do APL do município de Santa Rita do Sapucaí, MG, conhecido como o Vale da Eletrônica. Existe uma associação gestora do APL, chamada SINDVEL, responsável por reunir as empresas em torno de objetivos comuns. De acordo com a entidade, existem 67 indústrias do segmento eletroeletrônico associadas (Sindicato das Indústrias de Aparelhos Elétricos, Eletrônicos e Similares do Vale da Eletrônica, 2007). A escolha das empresas e do APL justifica-se pela complexidade do processo de suprimentos do setor eletroeletrônico, já que elas possuem uma grande variedade de itens comprados, entre eles componentes eletrônicos, placas e insumos eletromecânicos. Além disto, as evidentes características de aglomerados com fatores de eficiência coletiva, a representatividade do APL no cenário nacional e a facilidade de acesso às empresas pelo pesquisador foram determinantes para a escolha do Vale da Eletrônica.
0 Vale da Eletrônica possui duas características favoráveis a iniciativas coletivas e a ações conjuntas de acordo com Suzigan et al. (2007): 1) a composição de PMEs, ao passo que grandes empresas inibem ações de ordem coletiva, e 2) os produtos de alta tecnologia são mais propícios a envolverem empresas em cooperação relacionadas com P\&D.

Além disto, o APL pode ser caracterizado como um aglomerado pela existência dos fatores de Humphrey \& Schmitz (1998), que ajudam no alcance do benefício geral de eficiência coletiva:

- Divisão do trabalho e da especialização entre produtores e fornecedores de matérias-primas e de máquinas - Este fator foi observado nas empresas entrevistadas que possuíam uma parte significativa de seus suprimentos fornecidos por outras empresas pertencentes ao APL;

- Uma classe de trabalhadores assalariados com qualificações e habilidades específicas - Este fator manifesta-se com intensidade, através da integração que as faculdades INATEL, FAl e a escola ETE promovem com as empresas, funcionando como um repositório de funcionários com habilidades específicas em eletrônica, telecomunicações e informática; e

- Associações para a realização de lobbye de tarefas específicas para o conjunto de seus integrantes - A SINDVEL é uma associação gestora que facilita às empresas o alcance de uma série de benefícios como participação em feiras internacionais para a venda de produtos, a certificação $\mathrm{ISO}$, programas de excelência empresarial etc.

Tabela 1. Características definidas para a escolha dos itens para as entrevistas.

\begin{tabular}{|c|c|c|c|c|}
\hline \multicolumn{5}{|c|}{ itens } \\
\hline & 1 & 2 & 3 & 4 \\
\hline Insumo... & $x$ & $x$ & & \\
\hline Compra... & $x$ & $x$ & & \\
\hline Tecno... & Alta & Alta & Baixa & baixa \\
\hline \% no valor... & alta & Baixa/média & alta & Baixa/media \\
\hline
\end{tabular}

\begin{tabular}{|c|c|}
\hline $\begin{array}{l}\text { 1) Avaliação e posicionamento dos } 4 \text { itens de } \\
\text { análise sob os fatores de Olsen \&t Ellram (1997) }\end{array}$ & $\begin{array}{l}\text { Objetivo: Compreender as demandas } \\
\text { por relacionamentos com fornecedores } \\
\text { para itens distintos de compras }\end{array}$ \\
\hline $\begin{array}{l}\text { 2) Procedimentos de compras e relacionamentos } \\
\text { com fornecedores para os quatro itens }\end{array}$ & Objetivo: Analisar os relacionamentos \\
\hline$\downarrow$ & \\
\hline $\begin{array}{l}\text { 3) Aspectos gerais de compras e relacionamentos } \\
\text { com fornecedores }\end{array}$ & setor de compras \\
\hline 1 & Objetivo: Analisar as relações internas \\
\hline $\begin{array}{l}\text { 4) Relacionamento com as empresas e a } \\
\text { associação gestora do APL }\end{array}$ & $\begin{array}{l}\text { no } A P L \text { e as possíveis influências destas } \\
\text { nos relacionamentos com fornecedores } \\
\text { internos e externos ao } A P L\end{array}$ \\
\hline
\end{tabular}

Figura 3. Etapas das entrevistas com as empresas estudadas. 
A seleção de cinco casos, denominados empresa Alfa, Beta, Gama, Delta e Ômega, teve como objetivo buscar empresas de diferentes segmentos do mercado eletroeletrônico, tamanho (número de funcionários) e tempo de existência, conforme Tabela 2.

Esse tipo de seleção de objetos com características distintas foi recomendado por Eisenhardt (1989) e Voss et al. (2002), a fim de tornar a pesquisa mais robusta. Eisenhardt (1989) também indica que a escolha de quatro a 10 casos é apropriada ao método.

\section{Resultados da pesquisa}

Apresentam-se nos resultados da pesquisa as necessidades das empresas no relacionamento com fornecedores, os relacionamentos praticados com os fornecedores, a estruturação do setor de compras nas empresas e o relacionamento das empresas com o APL.

\subsection{As necessidades no relacionamento com fornecedores e as categorias das compras}

Nessa etapa foram avaliados os fatores apresentados por Olsen \& Ellram (1997). A partir das avaliações foram observadas as demandas no relacionamento com fornecedores para cada um dos itens de compra avaliados. Conforme os resultados da pesquisa, a demanda por parceria tecnológica está relacionada aos fatores: competência, novidade e complexidade do produto, e a demanda por parceria operacional está vinculada aos fatores: econômico, de imagem e mercado fornecedor, conforme apresentado no Tabela 3. Devido à dificuldade apresentada pelo entrevistado (caso piloto) de inferir sobre o fator característica externa, esta pesquisa não considerou esse fator originalmente sugerido por Olsen \& Ellram (1997).

No eixo de importância estratégica da compra, o fator competência foi considerado como o mais importante para três empresas (Alfa, Beta e Ômega) das cinco envolvidas no estudo. Esse fato destaca a forte preocupação com o desenvolvimento tecnológico a partir dos itens de compra (itens 1 e 3 ) e dos fornecedores, o que revela a necessidade de parcerias tecnológicas e a dependência tecnológica de seus fornecedores, compreensível em empresas cujos produtos são confeccionados com a montagem de diversos componentes eletrônicos. No entanto, as outras duas empresas, Gama e Delta, não possuem estratégia de crescimento no desenvolvimento tecnológico a partir dos itens de compra. Além de comercializarem itens de menor complexidade tecnológica, as empresas almejam apenas bons resultados operacionais para se sustentar no mercado, em função disto possuem uma demanda de parcerias com fornecedor inferior.

Ao segundo fator, econômico, foi atribuído peso de média importância para o desenvolvimento das empresas. Apesar da limitação de recurso financeiro ser um dos aspectos restritivos de PMEs citados por MacGregor et al. (2005), isso não influencia a ponto de tornar esse fator preponderante na avaliação de importância estratégica da compra. Existe um reconhecimento por parte dos entrevistados que é limitado ao espaço de negociação por preços em virtude do baixo volume de compra, quando comparado às vendas dos grandes fornecedores. Esse fator indicou a necessidade de parcerias operacionais, principalmente para os itens com volumes físicos e financeiros significativos (itens 1 e 2). Já o fator imagem não possui relevância na estratégia de compra das empresas, pois o peso atribuído foi de importância muito baixa.

No eixo Dificuldade de gerenciar a compra, os fatores considerados na avaliação foram dois: características de produto e mercado fornecedor. Esses dois fatores foram equiparados pelas empresas em relação ao peso de Dificuldade de gerenciar a compra. 0 fator característica do produto está subdividido em novidade e complexidade do produto.

Tabela 2. Descrição das particularidades das empresas selecionadas.

\begin{tabular}{|l|c|c|c|l|l|}
\hline Empresa & $\begin{array}{c}\text { N. de } \\
\text { pessoas }\end{array}$ & $\begin{array}{c}\text { Tempo } \\
\text { (em anos) }\end{array}$ & $\begin{array}{c}\text { N. de } \\
\text { Produtos }\end{array}$ & \multicolumn{1}{|c|}{ Atuação } & Particularidades \\
\hline Alfa & 150 & 25 & 110 & $\begin{array}{l}\text { Telecomunicações - Ramos de } \\
\text { telefonia }\end{array}$ & $\begin{array}{l}\text { Uma das maiores empresas; } \\
\text { Variedade reduzida de produtos e itens de compra; } \\
\text { Alta tecnologia. }\end{array}$ \\
\hline Beta & 250 & 33 & 8000 & Automação industrial & $\begin{array}{l}\text { Uma das maiores empresas; } \\
\text { Alta variedade de produtos e itens de compra; } \\
\text { Alta tecnologia. }\end{array}$ \\
\hline Gama & 90 & 23 & 1800 & Telecomunicações - Antenas & $\begin{array}{l}\text { Alta variedade de produtos e itens de compra; } \\
\text { Baixa tecnologia. }\end{array}$ \\
\hline Delta & 70 & 12 & 200 & Serviços de manufatura eletrônica & $\begin{array}{l}\text { Terceirização de manufatura; } \\
\text { Prestadora de serviços; } \\
\text { Fornecedores definidos/ priorizados pelos clientes. }\end{array}$ \\
\hline Ômega & 60 & 6 & 40 & Telecomunicações - Transmissores & $\begin{array}{l}\text { Uma das menores e mais novas empresas; } \\
\text { Alta tecnologia. }\end{array}$ \\
\hline
\end{tabular}


No critério novidade questionou-se sobre a frequência de inovações do produto comprado.

As empresas Alfa, Beta e Ômega possuem apenas uma compra (item 1 ou 3) dentre as avaliadas como de frequência alta de novas versões realizadas pelo fornecedor. Em ambos os casos, a inovação do fornecedor ocorre da forma unilateral, ou seja, as empresas são apenas comunicadas sobre as modificações. lsso se deve à assimetria de poder (baixo poder de compra), pois as empresas do APL

Tabela 3. Avaliação dos itens de compra estudados conforme método de Olsen \& Ellram (1997).

\begin{tabular}{|c|c|c|c|c|c|}
\hline & Fator & $\begin{array}{l}\text { Necessidade por } \\
\text { parcerias }\end{array}$ & Empresas & $\begin{array}{c}\text { Peso do fator } \\
(1-9) \text { - Grau de importância } \\
\text { relativa } \\
1 \text { - lgualmente } \\
3 \text { - Pouco mais } \\
5 \text { - Mais } \\
7 \text { - Muito Mais } \\
9 \text { - Absolutamente }\end{array}$ & $\begin{array}{c}\text { Itens de compra com maior } \\
\text { importância no fator (1-9) } \\
1 \text { - Muito Baixa } 7 \text { - Alta } \\
3 \text { - Baixa } 9 \text { - Muito Alta } \\
5 \text { - Moderada }\end{array}$ \\
\hline \multirow{15}{*}{ 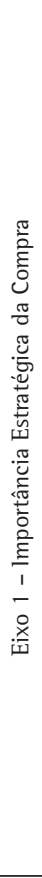 } & \multirow{5}{*}{$\begin{array}{c}\text { Competência } \\
\text { (Comparado ao econômico) }\end{array}$} & \multirow{5}{*}{ Parceria Tecnológica } & Alfa & 3 & $\begin{array}{l}\text { 1tem1 - Módulo GSM (9), } \\
\text { 1tem3 - Circuito Integrado (7) }\end{array}$ \\
\hline & & & Beta & 3 & $\begin{array}{c}\text { 1tem } 1 \text { - Circuito Integrado (9), } \\
\text { 1tem3-Conversor Analógico- } \\
\text { Digital (7) }\end{array}$ \\
\hline & & & Gama & 1 & $\begin{array}{c}\text { 1tem } 1 \text { - Conector (7), } \\
\text { 1tem } 3 \text { - Carga de Teste (9) }\end{array}$ \\
\hline & & & Delta & 1 & $\begin{array}{c}\text { 1tem2 - Placa para circuito } \\
\text { impresso (9), 1tem3 - Módulo de } \\
\text { Áudio (9) }\end{array}$ \\
\hline & & & Ômega & 3 & $\begin{array}{c}\text { 1tem } 1 \text { - Transistor (7), } \\
\text { 1tem3-Placa para Circuito } \\
\text { Impresso (7) }\end{array}$ \\
\hline & \multirow{5}{*}{ Econômico } & \multirow{5}{*}{ Parceria Operacional } & Alfa & \multirow{5}{*}{$\begin{array}{c}1 \\
\text { (Peso igual a } 1 \text { por ser a base } \\
\text { de comparação do eixo) }\end{array}$} & 1tem1- Módulo GSM (9) \\
\hline & & & Beta & & $\begin{array}{c}\text { Item } 1 \text { - Circuito Integrado (9), } \\
\text { Item2 - Ferrites e Cabos (7) }\end{array}$ \\
\hline & & & Gama & & $\begin{array}{c}\text { 1tem1 - Conector (7) / } \\
\text { 1tem2 - Latão e Não ferrosos (9) }\end{array}$ \\
\hline & & & Delta & & $\begin{array}{c}\text { 1tem2- Placa para Circuito } \\
\text { Impresso (7) }\end{array}$ \\
\hline & & & Ômega & & 1tem 1 - Transistor (9) \\
\hline & \multirow{5}{*}{$\begin{array}{c}\text { lmagem } \\
\text { (Comparado ao econômico) }\end{array}$} & \multirow{5}{*}{ Parceria Operacional } & Alfa & \multirow{5}{*}{$\begin{array}{c}1 / 7 \\
\text { (Muito menos importante) }\end{array}$} & 1tem 1- Módulo GSM (5) \\
\hline & & & Beta & & Todos os 4 itens ( 1 ) \\
\hline & & & Gama & & Item 1 - Conector (5) \\
\hline & & & Delta & & 1tem 3- Módulo de Áudio (9) \\
\hline & & & Ômega & & Item 1 - Transistor (9) \\
\hline \multirow{15}{*}{ 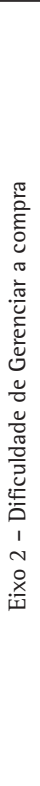 } & \multirow{5}{*}{$\begin{array}{l}\text { Característica do produto - } \\
\text { Novidade } \\
\text { (Comparado ao Mercado } \\
\text { Fornecedor) }\end{array}$} & \multirow{5}{*}{ Parceria Tecnológica } & Alfa & \multirow{5}{*}{$\begin{array}{l}\text { lgualmente importante } \\
\text { (Peso é 1/2 por ser uma } \\
\text { subdivisão do fator } \\
\text { Característica do Produto) }\end{array}$} & ltem 1 - Módulo GSM (7) \\
\hline & & & Beta & & $\begin{array}{c}\text { 1tem3- Conversor Analógico- } \\
\text { Digital (9) }\end{array}$ \\
\hline & & & Gama & & Item 1- Carga de Teste (3) \\
\hline & & & Delta & & $\begin{array}{c}\text { 1tem 2- Placa para circuito } \\
\text { impresso (3) }\end{array}$ \\
\hline & & & Ômega & & Item 1 - Transistor (7) \\
\hline & \multirow{5}{*}{$\begin{array}{l}\text { Característica do produto - } \\
\text { Complexidade } \\
\text { (Comparado ao Mercado } \\
\text { Fornecedor) }\end{array}$} & \multirow{5}{*}{ Parceria Tecnológica } & Alfa & \multirow{5}{*}{$\begin{array}{l}\text { lgualmente importante } \\
\text { (Peso é } 1 / 2 \text { por ser uma } \\
\text { subdivisão do fator } \\
\text { Característica do Produto) }\end{array}$} & $\begin{array}{c}\text { 1tem1 - Módulo GSM (9), } \\
\text { 1tem2 - SLIC (9), } \\
\text { 1tem3 - Circuito 1ntegrado (9) }\end{array}$ \\
\hline & & & Beta & & Item 1 - Circuito Integrado (9) \\
\hline & & & Gama & & 1tem 3- Módulo de Áudio (9) \\
\hline & & & Delta & & $\begin{array}{c}\text { 1tem } 2 \text { - Placa para circuito } \\
\text { impresso (9) }\end{array}$ \\
\hline & & & Ômega & & 1tem 1 - Transistor (9) \\
\hline & \multirow{5}{*}{ Mercado Fornecedor } & \multirow{5}{*}{ Parceria Operacional } & Alfa & \multirow{5}{*}{$\begin{array}{c}1 \\
\text { (Peso igual a } 1 \text { por ser a base } \\
\text { de comparação do eixo) }\end{array}$} & $\begin{array}{c}\text { 1tem1 - Módulo GSM (9), } \\
\text { 1tem3 - Circuito Integrado (9) }\end{array}$ \\
\hline & & & Beta & & $\begin{array}{c}\text { Item } 1 \text { - Circuito Integrado (9), } \\
\text { 1tem3- Conversor Analógico- } \\
\text { Digital (9) }\end{array}$ \\
\hline & & & Gama & & Todos os 4 itens (3) \\
\hline & & & Delta & & 1tem 3 - Módulo de Áudio (9) \\
\hline & & & Ômega & & 1tem 1 - Transistor (7) \\
\hline
\end{tabular}


não possuem representatividade junto a grandes fornecedores para restringirem suas modificações. A parceria de apoio técnico do fornecedor no sentido de possibilitar maior compreensão das tecnologias possui como uma de suas demandas a frequência de inovações e também a complexidade do produto.

Quanto ao fator mercado fornecedor, os itens 1 e 3 das empresas são os que apresentaram menor oferta e número de fornecedores alternativos. É importante destacar que os fornecedores desse item são grandes empresas e algumas dessas compras fazem parte de processos de importação intermediados por representantes e distribuidores. A exceção é a empresa Gama, que compra itens nacionais com nível de oferta considerável. Esse fator mostra o baixo poder de compra das empresas. Foi identificado na avaliação desse fator que para esses itens existe uma demanda de parcerias operacionais que assegurem o fornecimento, dada a vulnerabilidade das empresas frente aos grandes fornecedores.

A avaliação de cada fator foi realizada ponderando os valores ímpares entre um e nove da mesma forma sugerida por Narasimhan (1983). As atribuições desses valores e pesos conforme o Tabela 3 permitiram o posicionamento dos itens de compras na matriz de Kraljic (1983), apresentados na Figura 4. Vale ressaltar que a empresa Delta não identificou um item que se configurasse de acordo com as características do item 1, por isso só houve o apontamento dos itens 2, 3 e 4 para essa empresa.

Como síntese da Figura 4 e do Tabela 3 pode-se concluir que os itens de análise são distintos entre si, o que enriquece a pesquisa, e os itens 1 e 3 , de maneira geral, são os que apresentaram mais classificações dentro da categoria estratégico, por consequência, possuem maior necessidade de parcerias.

Logo, o item 2 possui menor demanda por relacionamento e somente de parceria operacional, enquanto que o item 4 é classificado como não crítico em todos os casos, ou seja, não há demanda de relacionamentos para o item.

\subsection{Relacionamentos das empresas com os fornecedores}

Nessa segunda etapa, foi questionado nas entrevistas quais eram os procedimentos que caracterizavam alguma parceria tecnológica ou operacional, ou se os relacionamentos eram puramente transacionais. Os principais relacionamentos que caracterizam um avanço na perspectiva de PMEs estão descritos no Tabela 4 (Mudambi et al., 2004).

É importante lembrar que PMEs compradoras possuem relacionamentos mais limitados com seus fornecedores devido aos aspectos internos, relacionados ao baixo nível do gerenciamento, e aos aspectos externos ligados ao mercado, conforme apresentado por MacGregor et al. (2005). Perona \& Saccani (2004) e Mudambi et al. (2004) preconizam que uma parceria deve estar sedimentada tanto na técnica de integração (gestão do relacionamento) quanto na ferramenta de integração que a operacionaliza. Nos casos pesquisados, as parcerias são bastante informais (sem uma gestão de relacionamento formalmente estabelecida). Não há nenhuma ferramenta de integração específica
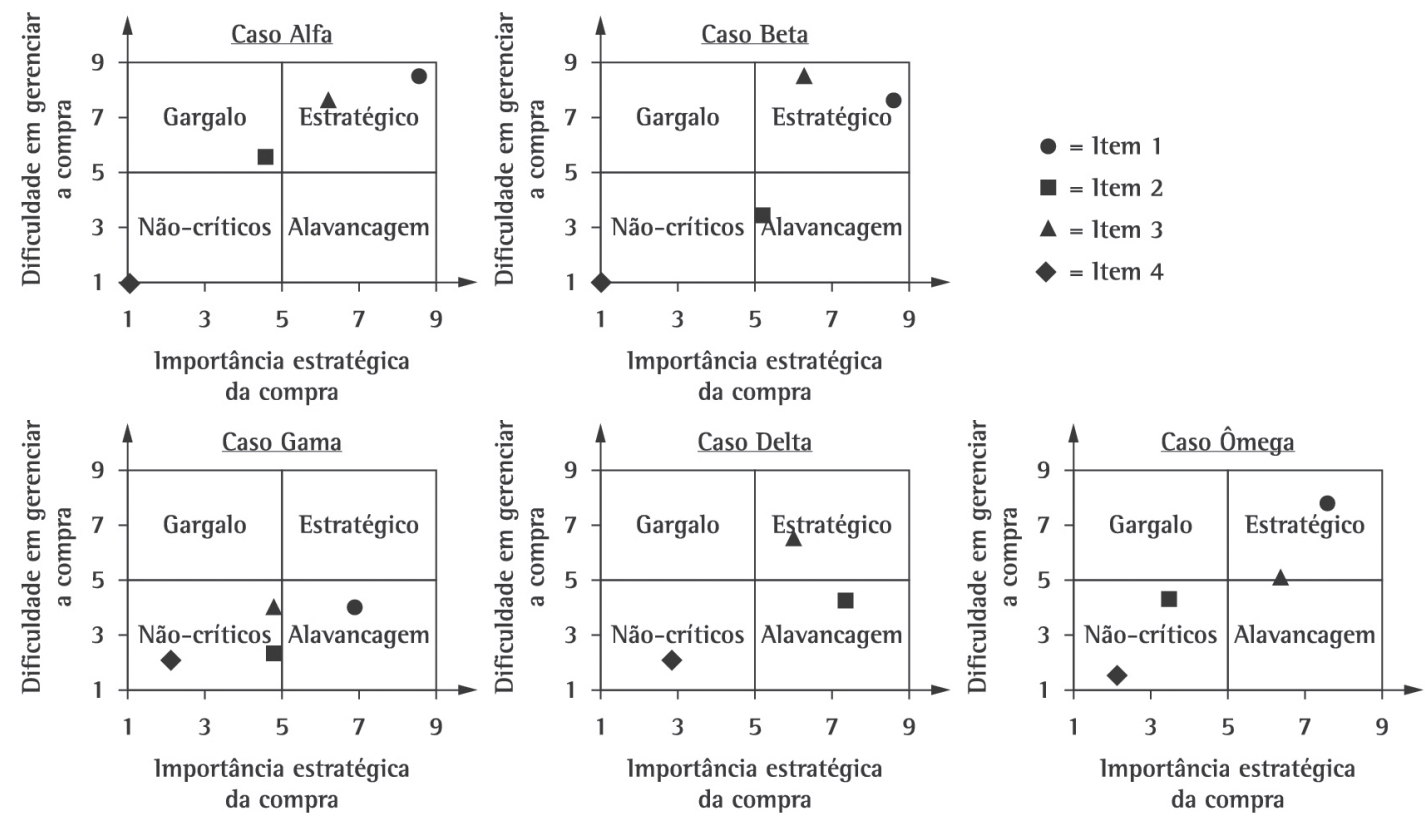

Figura 4. Posicionamento dos itens de análise na entrevista na matriz de Kraljic (1983). 
para o suporte de relacionamento com fornecedores. 0 que de fato existe para apoiar as parcerias são os mecanismos de comunicação (e-mails, telefonemas e visitas).

As organizações que apresentaram maior nível de parceria com fornecedores foram as empresas Alfa, Beta e Ômega - as quais têm um direcionamento maior ao desenvolvimento tecnológico a partir do item comprado, conforme descrito na seção anterior. Os itens 1 e 2 dessas empresas foram os que apresentaram maior nível de parcerias em função da importância estratégicas e de algumas facilidades e abordagens das empresas. As facilidades se encontram na presença do fornecedor no país (proximidade geográfica) e na ausência de intermediários (distribuidores).

Apesar da demanda de parceria tecnológica, os itens 3, nas empresas, são materiais importados de fabricantes e distribuidores e possuem como barreiras às parcerias o isolamento geográfico e o intermédio de distribuidores que se atêm à função de entregar o produto.

Algumas parcerias das empresas ocorrem por exigência ou iniciativa dos fornecedores. Outras são iniciativa da própria organização, como o caso da empresa Beta, que buscou através dos processos de desenvolvimento de produto e homologação o aumento do conhecimento técnico do funcionamento do item de compra. Outro caso é o da empresa Alfa, que buscou assegurar condições de fornecimento através de contrato e usou da concorrência entre dois grandes fornecedores para alcançar essa parceria operacional. É essencial para a consolidação de parcerias que as PMEs tenham iniciativas como as ilustradas nesta pesquisa junto aos fornecedores. Caso contrário os relacionamentos seguirão o formato de relacionamento transacional, o qual foi observado para a maior parte dos itens de análise nos cinco casos.

\subsection{Relacionamento das empresas estudadas com o APL Vale da Eletrônica}

As empresas estudadas participam da cadeia produtiva do APL como o último elo. Ocorre, por exemplo, o fornecimento de insumos mecânicos produzidos por empresas do APL para as empresas entrevistadas. Esse é um dos fatores de Humphrey \& Schmitz (1998) para o alcance de benefícios coletivos em APLs, a especialização produtiva das empresas. No contexto de parceria existem algumas evidências de parceria operacional e/ou tecnológica. De acordo com o entrevistado da empresa Ômega, os produtos são de baixo valor estratégico, por isso não há um relacionamento mais intenso. Entretanto, o entrevistado destaca que a proximidade geográfica facilita a comunicação com os fornecedores. Já as empresas Alfa e Beta possuem considerável parceria tecnológica pois, durante o desenvolvimento, desenvolvem as especificações e cronogramas junto com seus fornecedores do APL. Esses entrevistados afirmam priorizar o fornecedor dentro do APL devido às vantagens de um melhor relacionamento.

Quanto à cooperação horizontal, de maneira geral, as empresas possuem forte relacionamento com a associação gestora, com participação em feiras internacionais e outros eventos para promoção de vendas. Outro fato positivo é a inclusão das empresas em consultorias e certificações. A parceria com a Inatel também foi destacada nas entrevistas, pois a faculdade tem possibilitado financiamentos junto a instituições de amparo à pesquisa de projetos pioneiros no país, no caso da empresa Ômega. As empresas Alfa e Beta têm investido em projetos de desenvolvimento tecnológico coordenados pela Inatel. Esses dois são os elementos principais na parceria das empresas com o APL. 0 terceiro elemento de parceria são as empresas, mas não foi evidenciada nenhuma manifestação de parceria direta com as empresas do APL no contexto de cooperação horizontal. Um único fator inibidor apontado foi a presença de dois concorrentes diretos da empresa Ômega no APL.

Quanto às influências do APL nos relacionamentos com fornecedores das empresas pesquisadas foram observadas visitas periódicas de grandes fornecedores às empresas. Esse é um tipo de parceria tecnológica (Perona \& Saccani, 2004) que, segundo os entrevistados

Tabela 4. Parcerias tecnológicas e operacionais destacadas nas entrevistas.

\begin{tabular}{|l|l|l|}
\hline \multicolumn{1}{|c|}{ Itens definidos } & \multicolumn{1}{|c|}{ Parceria tecnológica } & \multicolumn{1}{c|}{ Parceria Operacional } \\
\hline $\begin{array}{l}\text { Item 1 } \\
\text { Módulo GSM / Transistor }\end{array}$ & $\begin{array}{l}\text { Assistência técnica para esclarecimentos do item para o } \\
\text { desenvolvimento do produto em visitas regulares/ mensais, e-mails e } \\
\text { telefonemas (Alfa, Ômega); }\end{array}$ & $\begin{array}{l}\text { Contrato de um ano (Alfa); } \\
\text { Envio de previsões de demanda (Alfa, } \\
\text { Ômega); }\end{array}$ \\
\hline $\begin{array}{l}\text { Item } 1 \\
\text { Circuito Integrado }\end{array}$ & $\begin{array}{l}\text { Durante o desenvolvimento de produto da empresa (Beta) e } \\
\text { homologação do item, a empresa visita o fornecedor a fim de obter } \\
\text { os conhecimentos necessários sobre o funcionamento do produto; }\end{array}$ & Não Observada; \\
\hline $\begin{array}{l}\text { Item } 2 \\
\text { Ferrites e Cabos / Hacks }\end{array}$ & $\begin{array}{l}\text { Discussão em visitas e reuniões sobre as especificações do novo } \\
\text { produto (Beta, Ômega); }\end{array}$ & $\begin{array}{l}\text { Emissão de relatórios de não } \\
\text { conformidade e indicador de defeitos / } \\
\text { indice PPM (Beta); }\end{array}$ \\
\hline $\begin{array}{l}\text { ltem } 3 \\
\text { Em geral }\end{array}$ & Não Observada; & Não Observada; \\
\hline $\begin{array}{l}\text { Item } 4 \\
\text { Caixa de Papelão }\end{array}$ & $\begin{array}{l}\text { Desenvolvimento do layout de embalagens através de visitas e e-mails } \\
\text { (etapa de cotação - Alfa); }\end{array}$ & Não Observada; \\
\hline
\end{tabular}




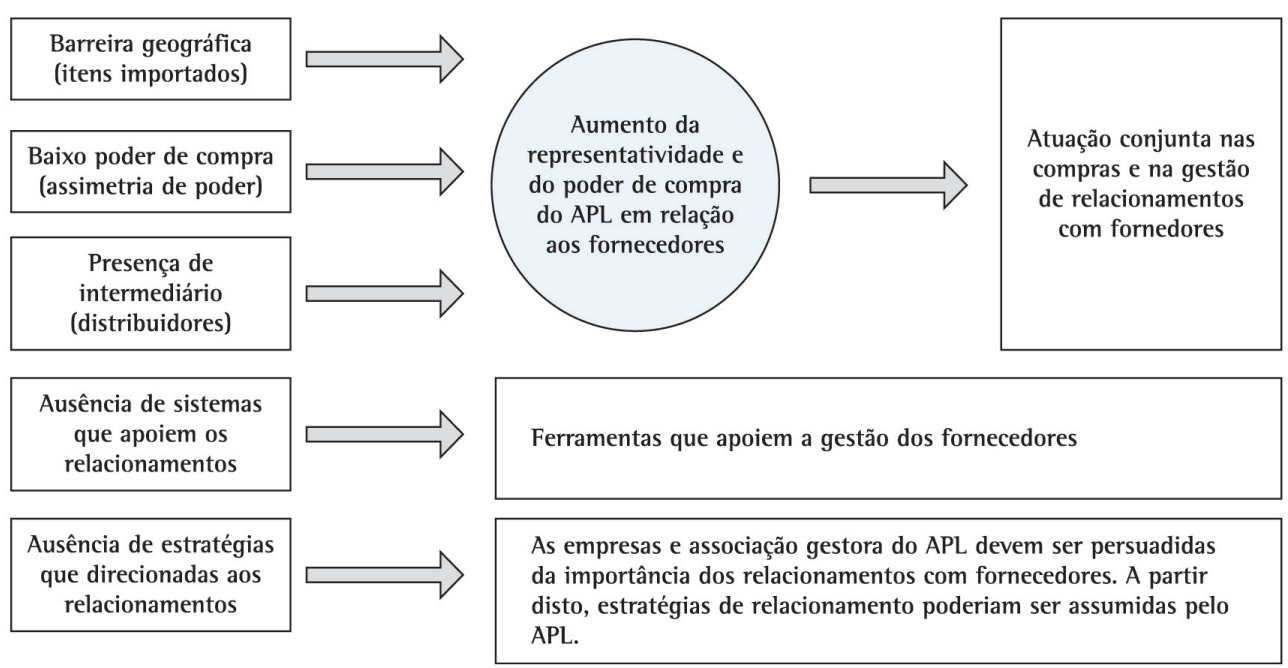

Figura 5. Oportunidades de melhorar o relacionamento com fornecedores do APL.

das empresas Alfa e Beta, é estendido a outras empresas do APL. Durante alguns dias, o engenheiro do fornecedor percorre uma série de empresas do APL não só para vender produtos como para prestar assistência técnica demandada pelas empresas. A natureza do APL possibilita essa constância de visitas devido ao aglomerado de empresas de mesma base tecnológica em uma mesma localização. Ou seja, o fornecedor não vê somente uma pequena ou média empresa, mas sim um grupo de empresas que constituem o APL, o que representa uma maior oportunidade de negócios e, por consequência, um melhor nível de parceria das empresas com o fornecedor.

Foi relatado também o caso da empresa Ômega, que obteve também uma vantagem natural do APL em relação aos suprimentos. 0 desenvolvimento do APL chamou a atenção de um fabricante suiço que visitou o arranjo para divulgar seus produtos e sua tecnologia. Nesse caso, a empresa foi beneficiada pela visibilidade do polo tecnológico, pois obtiveram um fornecedor com uma tecnologia que atendia de forma adequada suas necessidades. Esses dois casos mostram a importância de que os fornecedores vejam o APL como um todo e não cada empresa isoladamente.

\subsection{Dificuldades e potenciais de melhoria do relacionamento com fornecedores}

A partir das análises anteriores é possível diagnosticar que os casos não possuem uma relação proporcional entre demanda de relacionamentos com fornecedores e o relacionamento praticado. 0 item 3, em geral, é um exemplo, pois apesar de ocupar o quadrante estratégico e apresentar demandas de parceria tecnológica, não foi observada nenhuma parceria. Para itens como esse foram identificados alguns elementos que dificultam os relacionamentos com as empresas do APL: barreira geográfica (importação), baixo poder de compra, presença de intermediários (distribuidores), ausência de sistemas que suportem parcerias (uso de telefone, fax e e-mails) e ausência de estratégia para apoiar parcerias com fornecedores.

No entanto, existem alguns facilitadores que foram observados nos casos das empresas Alfa, Beta e Ômega - empresas com produtos de maior tecnologia e também mais dependentes da tecnologia do fornecedor - como a percepção dos benefícios do relacionamento, o uso da representatividade do APL e iniciativas para buscar essas parcerias com fornecedores.

Ante esses empecilhos e facilitadores identificados, os potenciais de melhoria estão na atuação conjunta das empresas do APL nas compras e na gestão de relacionamento com fornecedores, a fim de aumentar a representatividade e poder de compra do APL. É preciso que a associação gestora do APL - SINDVEL - estabeleça junto com as empresas estratégias de crescimento a partir da gestão do relacionamento com fornecedores. Essas estratégias deverão ser suportadas por ferramentas de integração como o compartilhamento de previsão de demanda, processamento de não conformidades e sistema de avaliação e seleção de fornecedores numa base de dados comum ao APL. Essas oportunidades de aumentar a visibilidade e representatividade das empresas, melhorar o nível de serviço e assistência do fornecedor estão ilustradas no esquema da Figura 5.

\section{Conclusões}

Dadas as defasagens das PMEs na gestão de relacionamento com fornecedores e de a capacidade 
de arranjos produtivos locais superar limitações das PMEs, o objetivo deste trabalho foi analisar as necessidades de relacionamento com fornecedores das empresas estudadas, como são os relacionamentos praticados com fornecedores de empresas do arranjo produtivo local (APL) - o Vale da Eletrônica, quais são as influências da cooperação interna do APL nesses relacionamentos com seus fornecedores e quais são as principais dificuldades e potenciais de melhoria.

A pesquisa revelou que existe uma elevada necessidade de parcerias tecnológicas nas empresas do APL (Alfa, Beta e Ômega). Essas empresas visualizam crescimento por meio de uma maior compreensão da tecnologia dos itens comprados. Além disso, existe uma gama de itens comprados aos quais os fornecedores frequentemente incorporam inovações, tendo as empresas muitas vezes que readequarem-se ou submeterem-se a um novo desenvolvimento de produto.

Já a demanda de parceria operacional no relacionamento com fornecedores é menos intensa para o APL. Até mesmo os itens com maiores volumes de compra não justificam esforços em parcerias para reduzir custos de transporte e armazenagem. A parceria operacional mais indicada foi o compartilhamento de previsões de demanda. 0 fator mercado fornecedor possibilitou visualizar os itens que demandam parcerias operacionais que assegurem os fornecimentos, como contratos.

Além das necessidades de relacionamento com fornecedores, a pesquisa também mostrou que os relacionamentos praticados com fornecedores das empresas do Vale da Eletrônica são básicos e informais, ou seja, não há uma gestão formal (técnica de integração) e um sistema (ferramenta de integração) para apoiá-los, conforme preconizam Perona \& Saccani (2004) e Mudambi et al. (2004). Em termos de ferramentas de integração, o que de fato existe para apoiar o relacionamento são meios de comunicação (e-mails, telefones e visitas). Apesar dos relacionamentos praticados serem elementares, podem-se destacar algumas práticas observadas nas empresas em relação à parceria tecnológica, como assistência técnica para auxiliar no desenvolvimento de um produto em que o item comprado é aplicado (comunicação frequente, incluindo visitas), homologação condicionada a visita técnica ao fornecedor e reuniões para definir especificações dos produtos comprados.

Em relação à parceria operacional, pode-se destacar o estabelecimento de contratos de curto prazo, envio de previsões de demanda e de indicadores de defeitos. Essas formas de parceria foram identificadas em alguns itens das empresas Alfa, Beta e Ômega. Nessas empresas também foi possível constatar alguns facilitadores do relacionamento: a percepção dos benefícios resultantes das parcerias com fornecedores, a representatividade do APL e iniciativas para buscar parcerias. É importante destacar que essas empresas produzem produtos com maior complexidade tecnológica, o que certamente influencia as empresas a reconhecerem mais facilmente os benefícios do relacionamento com fornecedores.

Por outro lado foi observada também a inexistência de parcerias para determinados itens, cujas características são restritivas no relacionamento dos fornecedores com as empresas: assimetria de poder (baixo poder de compra), barreira geográfica (importação) e presença de intermediários (distribuidores ou representantes). Além desses aspectos restritivos, podem ser incluídos dois outros que afetam todos os itens e todas as empresas: a falta de sistemas (ferramentas) que suportem os relacionamentos e a falta de estratégias (técnicas) das empresas na busca de parcerias com fornecedores.

Com relação à influência dos ganhos de eficiência coletiva no relacionamento com fornecedores, este trabalho identificou em dois casos (Alfa e Beta) a assistência técnica regular de grandes fornecedores no APL. 0 principal fator que explica essa parceria é que nessas visitas o representante do fornecedor visita não só uma empresa, mas um conjunto de empresas.

Em face dessa realidade dos relacionamentos com fornecedores, as principais oportunidades de evolução para o arranjo produtivo local estão em ações conjuntas em compras e gestão de relacionamento com fornecedores, pois permitem o aumento do poder de compra e a representatividade das empresas, dado que o fornecedor será visto não por uma empresa, mas por um número maior de empresas que compõem o arranjo.

Esta pesquisa se ateve à caracterização dos relacionamentos com fornecedores do APL, as principais dificuldades e potenciais de melhoria sob a perspectiva restritiva das PMEs e às vantagens da cooperação interna do APL através do estudo de cinco casos. Todavia, uma survey sobre relacionamento com fornecedores nos APLs pode compor pesquisas futuras, utilizando as descrições feitas neste trabalho sobre os relacionamentos com fornecedores. Assim, possibilitarão generalizar conclusões sobre o nível de relacionamento praticado, os aspectos facilitadores e os empecilhos aos relacionamentos com fornecedores em APLs.

\section{Referências}

Amato Neto, J. (2000). Redes de cooperação produtiva e clusters regionais: oportunidades para pequenas e médias empresas. São Paulo: Atlas. 
Collins, J., \& Hussey, R. (2005). Pesquisa em Administração. Porto Alegre: Bookman.

Eisenhardt, K. M. (1989). Building Theories from Case Study Research. Academy of Management Review, 14(4), 532550.

Gelderman, C. J., \& Van Weele, A. J. (2002). Strategic direction through purchasing portfolio management: A case study. Journal of Supply Chain Management, 38(2), 30-37. http://dx.doi.org/10.1111/j.1745-493X.2002.tb00127.x

Gelderman, C. J. (2003). Handling measurement and strategic issues in Kraljic's portfolio model -results of explorative case studies. Journal of Purchasing \& Supply Management, 9(6), 207-216. http://dx.doi. org/10.1016/j.pursup.2003.07.001

Humphrey, J., \& Schmitz, H. (1998). Trust and inter-firm relations in developing and transition economies. IDSUniversity of Sussex.

Instituto Brasileiro de Geografia e Estatística - IBGE. (2006). Pesquisa Industrial Anual. Empresa (Vol. 25, n. 1). IBGE.

Kraljic, P. (1983). Purchasing Must Become Supply Management. Harvard Business Review, 61, 109-117.

Lilliecreutz, J., \& Ydreskog, L. (1999). Supplier classification as an enabler for a differentiated purchasing strategy. Global Purchasing \& Supply Chain Management, 11, 66-74.

MacGregor, R. C., Vrazalic, L., Carlssen, S., Pratt, J. \& Harris, M. (2005). How Standard are the Standard barriers to E-commerce Adoption? A Comparison of Three Studies Carried out in Australia, Sweden and the US. Scandinavian Conference on Information Systems.

Miguel, P. (2007). Estudo de caso na engenharia de produção: estruturação e recomendações para sua condução. Produção, 17(1), 216-229. http://dx.doi.org/10.1590/ S0103-65132007000100015

Mudambi, R., Schründer, C., Mongar, A. (2004). How Cooperative is Co-operative Purchasing in Smaller Firms? Long Range Planning, 37, 85-102. http://dx.doi. org/10.1016/j.lrp.2003.11.007

Narasimhan, R. (1983). An Analytical Approach to Supplier Selection. Journal of Purchasing and Materials Management, 19, 27-32.
Olsen, R. F., \& Ellram, L. M. (1997). A Portfolio Approach to Supplier Relationships. Industrial Marketing Management, 26, 101-113. http://dx.doi.org/10.1016/ S0019-8501(96)00089-2

Perona, M. \& Saccani, N. (2004). Integration Techniques in customer-supplier relationship: A empirical research in the ltalian industry of household appliances. International Journal of Production Economics, 89, 189-205. http:// dx.doi.org/10.1016/S0925-5273(03)00012-4

Porter, M. (1998). Vantagem Competitiva. Criando e sustentando um desempenho superior (13. ed.). Rio de Janeiro: Campus.

Saccani, N., \& Perona, M. (2007). Shaping buyer-supplier relationships in manufacturing contexts: Design and test of a contingency model. Journal of Purchasing \& Supply Management, 13, 26-41. http://dx.doi.org/10.1016/j. pursup.2007.03.003

Sebrae. (2007). Arranjos produtivos locais. Retrieved from http://www.sebrae.com.br/br/cooperecrescer/ arranjosprodutivoslocais.asp.

Sindicato das Indústrias de Aparelhos Elétricos, Eletrônicos e Similares do Vale da Eletrônica - SINDVEL. (2007). Economia: Santa Rita do Sapucaí. Retrieved from http:// www.fiemg.org.br/Default.aspx?tabid=775.

Spekman, R. E., \& Hill, R. P. (1980). Strategy to effective procurement in the 1980s. Journal of Purchasing and Materials Management, 16(1), 2-6.

Suzigan, W., Garcia, R., \& Furtado, J. (2007). Estruturas de governança em arranjos ou sistemas locais de produção. Gestão \& Produção, 14(2), 425-439. http://dx.doi. org/10.1590/S0104-530X2007000200017

Van Weele, A. J. (2002). Purchasing and Supply Chain Management. London: Thomson Learning.

Voss, C., Sikriktsis, N., \& Frohlich, M. (2002). Case Research in Operations Management. International Journal of Operations and Production Management, 22(2), 195219. http://dx.doi.org/10.1108/01443570210414329

Yin, R. K. (1994). Case study research: Design and Methods. London: Sage Publications.

\title{
Supplier relationship management in clusters: the Electronics Valley case
}

\begin{abstract}
This study examines the supplier relationship management (SRM) through the approach of Olsen \& Ellram in five small and medium enterprises located in the Electronics Valley Cluster, Brazil. It is an exploratory descriptive study with data collection performed through interviews with executives of these five companies. It was possible to conclude that there is a strong need for technology partnerships with suppliers because of the possibility of competitiveness growth associated with supplier technology. However, relationships with suppliers are still incipient and informal, with no support strategies and systems integration. Because of the use of high technology inputs, integration with suppliers presents a great potential to improve the competitiveness of the enterprises in this cluster. However, in order to foster this potential, the cluster and its institutions need to develop incentive policies and joint actions.
\end{abstract}

Keywords

Supplier relationships management. Cluster. Small and medium enterprises. 